\title{
Leukaemia in children of Jehovah's Witnesses: issues and priorities in a conflict of care
}

\author{
P J Kearney Department of Child Health, Royal Hospital for Sick Children, Bristol
}

Throughout this paper P $\mathcal{F}$ Kearney attempts to balance the risks and benefits of different approaches in paediatric oncology. Decisions have to be considered both in the short and the long term. Where religious beliefs, such as those held by fehovah's Witnesses in relation to blood transfusions, conflict with normal medical practice the decision is often removed from the doctor, parents or patient to the courts. This sort of solution can be counter-productive, especially as good health care and subsequent recovery rely, to a large extent, on good relationships between and among the parties concerned. Destruction of these relationships, for whatever reason, often has a detrimental effect on the patient, in whose best interest everyone believes they are acting.

\section{Introduction}

The power of parents over the life and death of their children has been taken for granted by most cultures. In western Europe infanticide was common until the I9th century; whipping, sexual abuse, abandonment, and castration of children are all part of recent history ${ }^{1}$ : and it is likely that most circumcisions and tonsillectomies carried out in the recent past will be viewed with incredulity in the future. The twentieth century illusion of an idealized childhood and family contributed to our inability to recognise child abuse until the rg6os; for parental violence is almost certainly not just part of the high-rise syndrome, but the tailend of a long saga of parents' inhumanity to their children. We tend not to recognise parent power as such but it remains overwhelming in young children; and it is this age group which is most susceptible to childhood cancer. This power is undiluted in childhood illnesses when medical recommendations are made in loco parentis; for children cannot represent their point of view, but are dependent on the ability of parents and physicians to understand and interpret their wishes. Fortunately for most children, parent power is tempered by love and affection. Nevertheless, the medical profession's failure to recognise parental violence until recently remains a worrisome reflection on our inability to see beyond the conditioning of our cultural milieu.

The child with cancer is terribly vulnerable to medical decisions aided by parental power, so it is essential that doctors and parents are not consulted like the oracle; on the contrary their opinions must in be subjected to fair scrutiny. Careful analyses of $\overrightarrow{0}$ the risk-benefit ratios of decisions should be mandatory; otherwise the needs of the child can be $\vec{\omega}$ easily misguided by parental anxiety, or supplanted by the demands of research and medico-legal practice. The main difficulty is that our ability to identify errors in decision-making is very limited, $\vec{\omega}$ and this is probably because we lack a vocabulary $N$ to articulate about the decision-making process. $\frac{}{3}$ The models of relationship were introduced with this objective in mind and are used here to discuss issues raised during remission induction of acute $\stackrel{\vec{\rho}}{\square}$ lymphoblastic leukaemia (ALL) in children? whose parents are Jehovah's Witnesses.

\section{Models of relationship}

Medical decisions are the complex product of many factors, and it may seem invidious to reduce the process to simple models. Nevertheless the child's $\stackrel{\square}{\perp}$ best interests may be forfeited unless both parents $\overrightarrow{\vec{F}}$ and doctors analyse their approach to medical and $\frac{}{3}$ ethical problems; and consequently clarify their? own overt and latent motives. Lloyd de Mause ${ }^{1}$ has? described three possible reactions in adults to children in need: projective, reversal and empathic. $\overline{\mathrm{D}}$ Models of relationship have been constructed from 0 these reactions ${ }^{2}$ and they are summarized in Table I. It is hoped that these models provide ao vocabulary which may help to clarify and analyse the decision-making process, particularly in re-음 lation to childhood cancer.

The projective relationship is familiar in the fairly common situation where parents project their own ambitions onto their children, and in the projective model the child really serves to $N$ express the parents' or the doctor's inner fears, N hopes and beliefs. The medical requirements of 0 the cancer are considered separately from the needs 0 of the child. Decisions are based on the adults personal reaction to the problems of the cancer, $\stackrel{?}{?}$ without considering the child. At best, projective $T$ decisions may coincide with the needs of the child $\stackrel{P}{P}$ but they are potentially sinister. In the reversal $\stackrel{\odot}{\triangle}$ model, the cancer is again considered separately $\underset{\mathbb{Q}}{\mathbb{Q}}$ from the child. Moreover, the child is no longer the $\bar{\sigma}$ focus of interest. In a doctor-patient reversal relationship, the doctor's own interests take pre-o응 cedence over those of the child - the ideal order of 
Table I The link between decisions and relationships

Decision making process

\begin{tabular}{lllll}
\hline & Basis & Assessment & Effect on treatment policy \\
\cline { 2 - 5 } Projective & Adults personal beliefs & $\begin{array}{l}\text { Usually unhelpful } \\
\text { as the beliefs tend } \\
\text { to be inflexible. }\end{array}$ & $\begin{array}{l}\text { Variable. At best may coincide } \\
\text { with needs of the child, but } \\
\text { potentially disastrous. }\end{array}$ \\
\begin{tabular}{llll} 
Melationship \\
\cline { 2 - 5 }
\end{tabular} & Reversal & $\begin{array}{l}\text { A clash of priorities, } \\
\text { often subtle, between the } \\
\text { adults and the children's } \\
\text { needs - precedence being } \\
\text { given to the adult. }\end{array}$ & $\begin{array}{l}\text { May clarify, and } \\
\text { therefore encourage } \\
\text { a change to an } \\
\text { empathic approach. }\end{array}$ & $\begin{array}{l}\text { Similar to projective but less } \\
\text { dangerous, as it is susceptible } \\
\text { to analysis - so persuasion may } \\
\text { be able to encourage an empathic } \\
\text { response. }\end{array}$ \\
\cline { 2 - 5 } & Empathic & $\begin{array}{l}\text { Sound medical and } \\
\text { parental practice. }\end{array}$ & $\begin{array}{l}\text { Reinforces empathic } \\
\text { approach. }\end{array}$ & $\begin{array}{l}\text { Advances the total interests } \\
\text { of the child. }\end{array}$ \\
\hline
\end{tabular}

priority has been reversed. The reversal motivation may be medico-legal, peer pressure, or research projects. These circumstances are often subtle and need careful analysis to realize that the interests of the child are not receiving first priority. The ideal empathic relationship takes all the needs of the child into consideration. This would include understanding the child's desire and will to live, which can justify unpleasant treatments.

The difficulty in the projective relationship is that the adults believe that their decisions are in the best interests of the child. Their hopes and fears which motivate them are ill understood, and like blind faith, can be difficult to alter. The reversal reaction, though often initially subconscious, can usually be clarified and exposed - allowing hope for a change in policy (Table I). It is important to emphasize that relationships are not fixed, but may change according to circumstances.

Medical decisions may be further qualified depending on whether they are proximal to, or are remote from the patient. The ideal empathic relationship would be proximal by its very nature as it demands a personal understanding of the child. Unfortunately, decisions are more often remote from the patient as there is a tradition of hierarchy in medicine. Protocols have a remote quality all of their own, particularly in clinical trials, when they have a formidable authority - often soundly based - but their remoteness from the patient makes them inflexible and unresponsive to some children's needs.

\section{Case reports}

Two children of different families whose parents are Jehovah's Witnesses recently presented to this hospital with ALL. Their clinical and haematological findings at diagnosis are shown in Table II. Treatment was started with daily oral prednisolone $40 \mathrm{mg}$ per $\mathrm{m}^{2}$ and weekly intravenous vincristine r.5 $\mathrm{mg}$ per $\mathrm{m}^{2}$. Blood transfusions were not given, and their initial haematological progress is shown in the figure. Haematological remission was confirmed by repeat bone marrow examinations. Subsequent CNS prophylaxis and maintenance treatment was given, based on Pinkel's regimen. ${ }^{3}$ At present both children remain in complete continuous remission over one year from diagnosis.

Table II Clinical and haematological findings at diagnosis

\begin{tabular}{lll}
\hline & Case I & Case 2 \\
\hline Age/Sex & 7 years/boy & 6 years/boy \\
Liver & $5 \mathrm{~cm}$ & $4 \mathrm{~cm}$ \\
Spleen & $3 \mathrm{~cm}$ & $8 \mathrm{~cm}$ \\
Nodes & $++/++++$ & $+++/+++$ \\
CNS & Normal & (R) subhyaloid and \\
& & (L) retinal haemorrhage \\
HB & $4.48 / \mathrm{dl}$ & $4.58 / \mathrm{dl}$ \\
WBC & $4800 / \mathrm{cmm}$ & $26000 / \mathrm{cmm}$ \\
Blasts & $52 \%$ & $40 \%$ \\
Platelets & $18000 / \mathrm{cmm}$ & $25000 / \mathrm{cmm}$ \\
Bone Marrow & Acute & Acute \\
& Lymphoblastic & Lymphoblastic \\
& Leukaemia & Leukaemia \\
& &
\end{tabular}

\section{Discussion}

The outlook for ALL has dramatically improved in the last decade. The chance of inducing a complete remission in these children was much better than 90 per cent, and they have in addition around a 50 per cent chance of a cure ${ }^{3}$; but this requires systemic treatment with cytotoxic drugs over a period of years and separate treatment of the central nervous system. The disease and its treatment are often very demanding on the emotional resources of the child, the parents and the doctors. The successful outcome demands close cooperation from all involved. The difficulties of managing childhood cancer are compounded in Jehovah's Witnesses because blood transfusions are an 
anathema to them; and it is not difficult to envisage a conflict between the medical needs of the children and the religious beliefs of the parents.

The risks and benefits of different approaches in paediatric oncology have to be considered both in the short and long term. Decisions are too often based on short term medical contingencies. This may be counter-productive if the short term gains are less important than the long term problems. In children with ALL the immediate dangers of anaemia and thrombocytopenia can normally be dealt with by the appropriate transfusions; until the child's own bone marrow cells regenerate. When transfusions have been a legal issue in children of Jehovah's Witnesses, the courts have decided in favour of giving blood ${ }^{4}$; and in the cases reported the medical indications for transfusions were unequivocal. The use of models help to clarify other considerations of the utmost importance to the children's welfare, and to support two related and superficially controversial decisions: the children were not included in clinical research trials as the relationships between paediatrician, parents and child needed decisions which could be flexible and responsive to the demands of the moment, and which were not predetermined by remote protocols. Secondly, a qualified policy of non-transfusion was adopted.

Despite some recent well-publicised misgivings ${ }^{5}$, it is still much more acceptable to die from overtreatment than from a disease. Medico-legal and peer pressures have synergised to advocate concepts of care in which over-treatment is more acceptable than a failure to perceive the total problem ${ }^{6}$. Doctors have not allowed themselves to take risks even for the sake of the patient. Most doctors respond to life-threatening illnesses in their patients with a decent empathic relationship. However, when faced with the difficult conundrum of choosing between a short term medical risk and the long term risk of family disruption, many doctors tend to be guided only by medical priorities. When the risk of family disruption is great, and the consequence serious for the child, there is a danger that the doctor's empathic relationship with his patient may slide almost imperceptibly into reverse. In the cases reported, it is suggested that an aggressive transfusion policy during remission induction would have ensured a reversal rather than an empathic relationship. In a subtle way, the doctor and the patient would have reversed their roles. The short term medical risks, though hardly significant compared with the long term problems of family disruption, would have been the doctor's prime concern. The paediatrician would have been motivated by his standing with his peers, research workers, and lawyers, and not by the overall needs of the child. The child would have been serving the doctor's professional needs.

Three of the four parents wanted to withhold transfusions, even if this directly threatened the child's life. In this circumstance, their reactions! were no longer ideal and empathic, but projective and menacing. The parents' reaction to their child's? need was to project their fears of Jehovah through $\overrightarrow{\vec{\overrightarrow{ }}}$ the child, even if the child's life was sacrificed. The parents were otherwise loving and considerate, and would in normal circumstances easily slot into the ideal empathic category. In case $I$, father had intimated that he would, if necessary, give per $\frac{\mathrm{O}}{0}$ mission for transfusion, though mother's ob ss jections remained adamant. In case 2 , the parents were united in their religious beliefs against blood transfusions. Father's permission would in case $\tilde{f}$ have been sufficient to obtain legal sanction but court order would have been necessary in case $2 \Phi$ Either solution would have been very counter ${ }^{+}$ productive. Direct confrontation of the problem $\overrightarrow{3}$ would undoubtedly have forced an unhappt projective reaction from three of the four parents? The result in case I could have been a source of major conflict between father and mother; ita case 2 the likely legal wrangle could only have deleterious effect on doctor-parent relationships. In both cases the children would have been the ultimate losers.

The parents' fundamental beliefs should not bह easily dismissed. A strong family unit is almose essential in the management of children with cancero Any factor which undermines this unit should nof be undertaken lightly. A conflict between the need $\$$ of treatment and the needs of the child require careful evaluation. The risks and benefits to bot the medical and the emotional needs of the child should be determined; so that the effects of medicas. intervention or non-intervention can be compared The long term benefit of the parents' ideal empathic relationship was clearly more important than the short term risks; provided the children's lives were not directly threatened. Obviously a non-transfusio policy involved medical risks, but these were mini mized by constant supervision of the children. The long term risks of an aggressive transfusion policy are less apparent. Analysis with models suggested. that the child was threatened by two oppositte extremes: not only by a projective parental reaction forbidding transfusions in any circumstance, bu also by a reversal reaction in the medical staftit advocating an aggressive transfusion policy. In the circumstances, a compromise of non-confrontatiom was adopted. The parents were keen to sign docu® ments which would not permit transfusion. This s $^{+}$ was successfully discouraged. The children werd kept in hospital on regular close observations, an compatible blood was kept in reserve. After two weeks, clear evidence of normal bone marrow regeneration was apparent (Fig I), and the risks of a non-transfusion policy had disappeared. In a lifen threatening emergency, transfusions would have been given. 


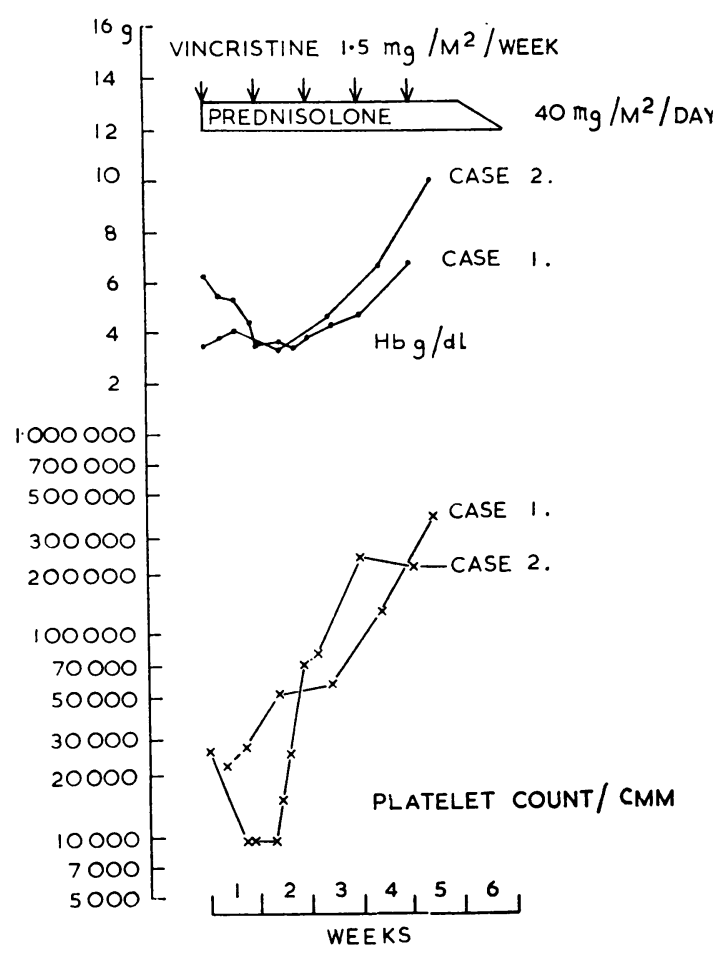

Fig I Treatment and haematological progress during remission induction.

The period of remission induction is critical in ALL. Future transfusions on standard treatments are extremely unlikely to be necessary once remission has been induced: unless the leukaemia relapses. On the other hand, if the disease relapses on adequate treatment, the prospect of a cure dwindles for practical purposes to zero. In these circumstances transfusions would not be lifesaving. Thus for these children the critical and controversial phase of treatment was during remission induction. The use of models helped to clarify the risk-benefit ratios and a satisfactory resolution of the crisis was obtained by conservative medical management.

\section{Acknowledgements}

I thank Professor N R Butler for permission to publish the case reports, and my wife, Siun, for her constructive criticisms. I acknowledge with thanks the support of the Ainsworth Scholarship, University College, Cork, Ireland.

\section{References}

${ }^{1}$ De Mause, L, The History of Childhood, r, De Mause, L, London, Souvenir Press (Educational and Academic) Ltd, 1976.

${ }^{2}$ Kearney, P J, Ethics, cancer and children, Medical Hypotheses, 3, 174-179, 1977.

3Simone, J, Aur, R J A, Husto, H O, Pinkel, D, Total therapy studies of acute lymphocyte leukaemia in children, Cancer, 30, I488-1494, 1972.

${ }^{4}$ Macklin, R, Consent, coercion and conflict of rights, Perspectives in Biology and Medicine, 20, 360-37I, 1977.

'Illich, I, Medical Nemesis, London, Calder and Boyars Ltd, 1975.

${ }^{6}$ Kearney, P J, Personal view, British Medical fournal, I, $1069,1976$. 